\title{
Protection against Fas-induced fulminant hepatic failure in liver specific integrin linked kinase knockout mice
}

\author{
Shashikiran Donthamsetty, Wendy M Mars, Anne Orr, Chuanyue Wu and George K Michalopoulos*
}

\begin{abstract}
Background: Programmed cell death or apoptosis is an essential process for tissue homeostasis. Hepatocyte apoptosis is a common mechanism to many forms of liver disease. This study was undertaken to test the role of ILK in hepatocyte survival and response to injury using a Jo-2-induced apoptosis model.

Methods: For survival experiments, ILK KO and WT mice received a single intraperitoneal injection of the agonistic anti-Fas monoclonal antibody Jo-2 at the lethal dose $(0.4 \mu \mathrm{g} / \mathrm{g}$ body weight) or sublethal dose $(0.16 \mu \mathrm{g} / \mathrm{g}$ body weight). For further mechanistic studies sublethal dose of Fas monoclonal antibody was chosen.

Results: There was 100\% mortality in the WT mice as compared to $50 \%$ in the KO mice. We also found that hepatocyte specific ILK KO mice (integrin linked kinase) died much later than WT mice after challenge with a lethal dose of Fas agonist Jo-2. At sublethal dose of Jo-2, there was $20 \%$ mortality in $\mathrm{KO}$ mice with minimal apoptosis whereas WT mice developed extensive apoptosis and liver injury leading to $70 \%$ mortality due to liver failure at $12 \mathrm{~h}$. Proteins known to be associated with cell survival/death were differentially expressed in the 2 groups. In ILK $\mathrm{KO}$ mice there was downregulation of proapoptotic genes and upregulation of antiapoptotic genes.

Conclusions: Mechanistic insights revealed that pro-survival pathways such as Akt, ERK1/2, and NFkB signaling were upregulated in the ILK KO mice. Inhibition of only NFKB and ERK1/2 signaling led to an increase in the susceptibility of ILK KO hepatocytes to Jo-2-induced apoptosis. These studies suggest that ILK elimination from hepatocytes protects against Jo-2 induced apoptosis by upregulating survival pathways. FAK decrease may also play a role in this process. The results presented show that the signaling effects of ILK related to these functions are mediated in part mediated through NFkB and ERK1/2 signaling.
\end{abstract}

Keywords: Integrin linked kinase, Jo-2, Apoptosis, ECM signaling

\section{Background}

Programmed cell death or apoptosis is an essential process for tissue homeostasis. Hepatocyte apoptosis is a common mechanism to many forms of liver disease. It has been recognized to contribute to the pathogenesis of alcoholic liver disease, nonalcoholic steatohepatitis, viral hepatitis, cholestatic liver disease, and ischemia/reperfusion injury [1-4]. Apoptosis can be triggered by Fas receptor mediated signaling as well as different stimuli that provoke cell stress. All these stimuli converge at the activation of caspase 3 that leads to internucleosomal DNA degradation,

\footnotetext{
* Correspondence: michalopoulosgk@upmc.edu
Department of Pathology, University of Pittsburgh School of Medicine,

* Correspondence: michalopoulosgk@upmc.edu
Department of Pathology, University of Pittsburgh School of Medicine, Pittsburgh, PA, USA
}

(c) 2011 Donthamsetty et al; licensee BioMed Central Ltd. This is an Open Access article distributed under the terms of the Creative Commons Attribution License (http://creativecommons.org/licenses/by/2.0), which permits unrestricted use, distribution, and reproduction in any medium, provided the original work is properly cited. small apoptotic bodies that are phagocytosed by neighboring macrophages [4]. The liver is very sensitive to Fasinduced apoptosis. Administration anti-Fas agonistic antibody Jo-2 to mice leads to rapid death of the animals due to fulminant hepatitis, mimicking certain forms of acute liver failure (ALF) in humans [5]. Fas (CD95/APO-1), a 43-kDa cell surface glycoprotein, belongs to the tumor necrosis factor receptor superfamily, and mediates apoptosis upon binding with its cognate ligand, or artificially with specific agonistic antibodies.

Communication between cells and the extracellular matrix (ECM) is achieved through integrins and the associated integrin proximal adhesion molecules. Through 
multiple protein-protein interactions and signaling events, these molecules transmit signals from the ECM to the interior of the cell and regulate many fundamental cellular processes. Integrin-linked kinase (ILK) is a $\beta 1$ - and $\beta 3$ integrin-interacting cell matrix adhesion protein that has been shown to be crucial for a number of cellular processes such as survival, differentiation, proliferation, migration, and angiogenesis [6-8]. Previous studies in our lab have shown that acute elimination of ILK by injection of adenovirus expressing Cre recombinase in the tail vein of ILKflox/flox mice led to massive hepatocyte apoptosis [9]. Genetic ablation of ILK also results in some degree of apoptosis [10] but also to an enhancement of hepatocyte proliferation, suggesting that ILK might be playing a role in hepatocyte survival. This study was undertaken to test the role of ILK in hepatocyte survival and response to injury using a Jo-2-induced apoptosis model. Here we report that genetic ablation of ILK from hepatocytes protects from Jo-2 induced apoptosis due to upregulation of survival signaling mainly ERK and $\mathrm{NF} \kappa \mathrm{B}$ signaling.

\section{Methods}

\section{Generation of liver specific ILK/liver-/- mice}

ILK floxed animals were generated as described previously [10] and donated by Drs. René St. Arnaud (Shriners Hospital and McGill University, Montréal) and Shoukat Deodhar (British Columbia Cancer Agency and Vancouver Hospital, Jack Bell Research Center, Vancouver), and mated with AFP-enhancer-albumin-promoter-Cre-recombinase-expressing mice which were kindly provided by Dr. Klaus Kaestner (University of Pennsylvania). The offspring were genotyped as described previously [11] and the ILK-floxed/floxed Cre-positive mice were considered to be ILK-knockout (ILK KO), while their Cre-negative siblings were used as controls. All animals were housed in the animal facility of the University of Pittsburgh in accordance with the guidelines of the Institutional Animal Use and Care Committee of the University of Pittsburgh.

\section{Induction of apoptosis}

For survival experiments, male 30 week-old ILK KO ( $\mathrm{n}=$ $10)$ and control mice $(n=10)$ received a single intraperitoneal injection of the agonistic anti-Fas monoclonal antibody Jo-2 (BD Pharmingen, San Diego, CA) at the lethal dose $(0.4 \mu \mathrm{g} / \mathrm{g}$ body weight $)$ or sublethal dose $(0.16 \mu \mathrm{g} / \mathrm{g}$ body weight) diluted in sterile saline. The mice were monitored for up to 24 hours, and the time of death was recorded. The Fas injury model was induced in controls and ILK KO mice with a single intraperitoneal injection of Jo-2 at the dose of $0.16 \mu \mathrm{g} / \mathrm{g}$ weight. At the indicated time points (up to 12 hours) after Jo-2 injection, mice were sacrificed. Livers were snap frozen in liquid nitrogen or formalin-fixed and paraffin embedded for histopathological studies. All procedures performed on these mice were approved under the IACUC protocol and conducted according to National Institute of Health guidelines.

Isolation, culture and treatment of mouse hepatocytes Hepatocytes were isolated from male ILK KO and control mice as described previously [10]. Cells were plated onto collagen-coated 6-well dishes (type I collagen, Collaborative Biomedical, Bedford, MA) $5 \times 10^{5}$ cells per well. Cultures were maintained in minimal essential medium supplemented with $10 \%$ fetal calf serum, nonessential amino acids, $2 \mathrm{mM}$ glutamine, and antibiotics (all from Invitrogen). After 2-h incubation medium was removed, and cells were refed the same medium with $0.5 \%$ fetal calf serum and incubated overnight. Apoptosis was induced in cultured mouse hepatocytes by treatment with $0.5 \mu \mathrm{g} / \mathrm{ml}$ anti-Fas antibody and $0.05 \mu \mathrm{g} / \mathrm{ml}$ actinomycin $\mathrm{D}$ as described before [12]. The effect of ILK deletion on Fas-mediated apoptosis was also tested in the presence of the extracellular-regulated kinase 1/2 inhibitor U0126 (20 $\mu \mathrm{M}$, Cell Signaling), the phosphatidylinositol 3-kinase (PI3K) inhibitor LY-294002 (50 $\mu \mathrm{M}$, Cell signaling) and NF $\kappa \mathrm{B}$ peptide (30 $\mu \mathrm{M}$, Calbiochem). Doses of the inhibitors and peptides were selected based on previous studies with isolated hepatocytes [13].

\section{Measurement of apoptosis}

Apoptotic nuclei were detected by terminal deoxynucleotidyl transferase-mediated deoxyuridine triphosphate nick-end labeling staining using the ApopTag Peroxidase kit (Millipore, Billerica, MA). Activation of caspase $3 / 7$ in cell lysates was detected using a commercially available kit (Promega, Madison, WI).

\section{Western blot analysis}

Liver Homogenates were prepared as described previously [10]. The following primary antibodies were used in this study: rabbit anti-cleaved caspase 3, Rabbit anti-BAD and phospho BAD, Rabbit anti-Bcl-2, Rabbit anti-Bcl-xl, Rabbit anti phospho Akt (serine 473), Rabbit anti phospho ERK (Thr202/Tyr204), Rabbit cleaved PARP, Rabbit p65 (Cell Signaling Technologies, Danvers, MA), Mouse anti Fas (Santa Cruz) and mouse anti- $\beta$-actin (Chemicon, Temecula, CA). Donkey antirabbit and anti-mouse secondary antibodies were purchased from Jackson ImmunoResearch Laboratories (West Grove, PA) and were used at 1:50,000 dilutions.

\section{Results}

Effect of genetic ablation of ILK from hepatocytes on Fasinduced animal death and fulminant hepatitis

To determine whether ILK may play a role in the regulation of hepatocyte survival from apoptosis inducing stimuli, we determined the sensitivity of mice lacking ILK to Fas-induced apoptosis. We injected ILK KO and 
control mice with a single intraperitoneal lethal dose $(0.4 \mu \mathrm{g} / \mathrm{g})$ of Jo- 2 . There was $50 \%$ mortality in the ILK $\mathrm{KO}(5 / 10)$ at 24 hours after Jo-2 injection, while all the controls died much faster than the ILK KO mice, showing $100 \%$ mortality $(10 / 10)$ by $7 \mathrm{~h}$ after challenge whereas ILK KO mice were still alive at this time point (Figure 1A). Next we analyzed the effect of a sublethal dose of Jo-2 antibody $(0.16 \mu \mathrm{g} / \mathrm{g})$ on the survival of ILK $\mathrm{KO}$ and control mice. With this lower dose of Jo-2, there was $20 \%$ mortality $(2 / 10)$ in the ILK KO mice while there was $70 \%$ mortality $(7 / 10)$ in control mice by $24 \mathrm{~h}$ (Figure 1A). These data suggested that genetic ablation of ILK from hepatocytes protected the mice against Fas-induced apoptosis. We then evaluated the degree of hepatocellular damage in ILK KO and control mice in response to the sublethal dose of Jo-2. Histological examination of liver samples obtained at $6 \mathrm{~h}$ after sublethal dose of Jo-2 showed a higher degree of liver injury and the presence of parenchymal hemorrhages in control mice but not in ILK KO mice (Figure 1B). The different response to Jo-2 observed in ILK KO and control mice could be attributable in part to reduced hepatic expression of Fas receptor, because the basal levels of Fas as determined by Western blotting was lower in the livers of the ILK KO liver (Figure 1C). The expression was also lower in the hepatocytes isolated from ILK $\mathrm{KO}$ mice compared to WT mice (Figure $1 \mathrm{C}$ ). Thus, it is likely that ILK regulates the expression of Fas receptor. Similarly, TUNEL assay of the liver sections demonstrated more abundant apoptotic nuclei in control mice than in ILK KO mice. Activation of capase3/7 was also higher in the control mice than ILK KO mice at 6 and $12 \mathrm{~h}$ after Jo-2 administration. In addition, expression of cleaved caspase 3 and PARP were also higher in the control than the ILK KO mice at both 6 and $12 \mathrm{~h}$ after a sublethal dose of Jo-2 (Figure 2A, B and 2C).

\section{Mechanism of protection of ILK KO mice against Jo-2 induced hepatic failure}

We looked at the protein expression of various anti apoptotic proteins involved in Fas-induced apoptosis. Bcl-2 family proteins inhibit apoptosis induced by variety of stimuli, including Fas mediated apoptosis $[1,14,15]$. We assessed the expression of the antiapoptotic protein Bcl$\mathrm{xL}$ and Bcl-2 by Western blotting at 0, 6 and $12 \mathrm{~h}$ after the injection of sublethal dose of anti-Fas antibody (Figure $2 \mathrm{C}$ ). Bcl-xL and Bcl-2 proteins levels were decreased in the liver of control mice treated with Jo2; however, in ILK KO mice Bcl-xl and Bcl-2 protein levels were maintain in response to a sublethal dose of Jo-2 (Figure 2C). The ILK KO mice also had higher expression of Bcl-2 at basal levels (Figure 2C). We also looked at the protein expression of Bcl-2-associated death promoter (BAD) after Jo-2 administration. Dephosphorylated BAD forms a heterodimer with $\mathrm{Bcl}-2$ and $\mathrm{Bcl}-\mathrm{xl}$, inactivating them, and thus allowing Fas-triggered apoptosis to take place. BAD phosphorylation is thus anti-apoptotic, and BAD dephosphorylation is pro-apoptotic [1]. In the control mice the BAD levels did not change before and after Jo-2 administration but there was an induction of BAD after Jo-2 administration in the ILK KO mice (Figure 2D). The expression of $\mathrm{p}-\mathrm{BAD}$ which is antiapoptotic was higher
A)

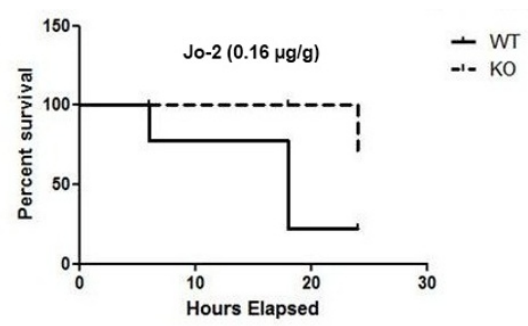

B)

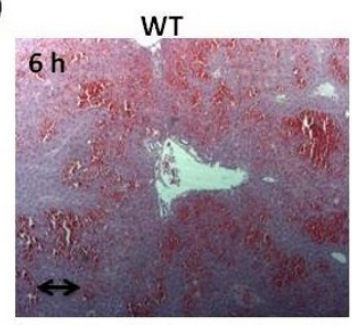

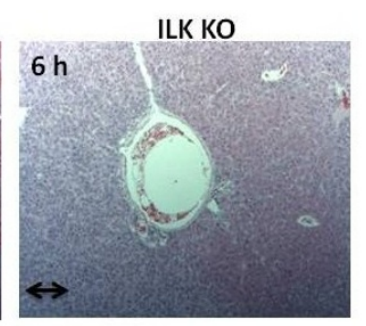

C)

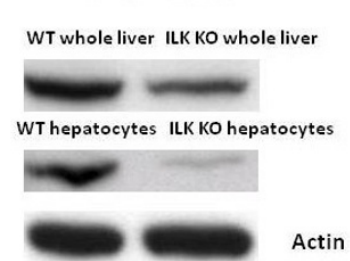

Figure 1 Protection of ILK KO mice against Fas-induced liver injury and apoptosis. A) Kaplan Meier survival curves after a sublethal (0.16 $\mu \mathrm{g} / \mathrm{g}$ ) (left graph) and a lethal dose $(0.40 \mu \mathrm{g} / \mathrm{g}$ ) (right graph) of Jo-2. B) Hematoxylin-eosin staining of liver sections at $6 \mathrm{~h}$ after a sublethal injection of Jo-2 shows reduced hemorrhage and apoptotic cell bodies in the ILK KO mice. Double arrow $=300 \mu \mathrm{m}$. C) Representative Western blots of basal levels of Fas receptor in whole livers and hepatocytes isolated from WT and ILK KO mice. 


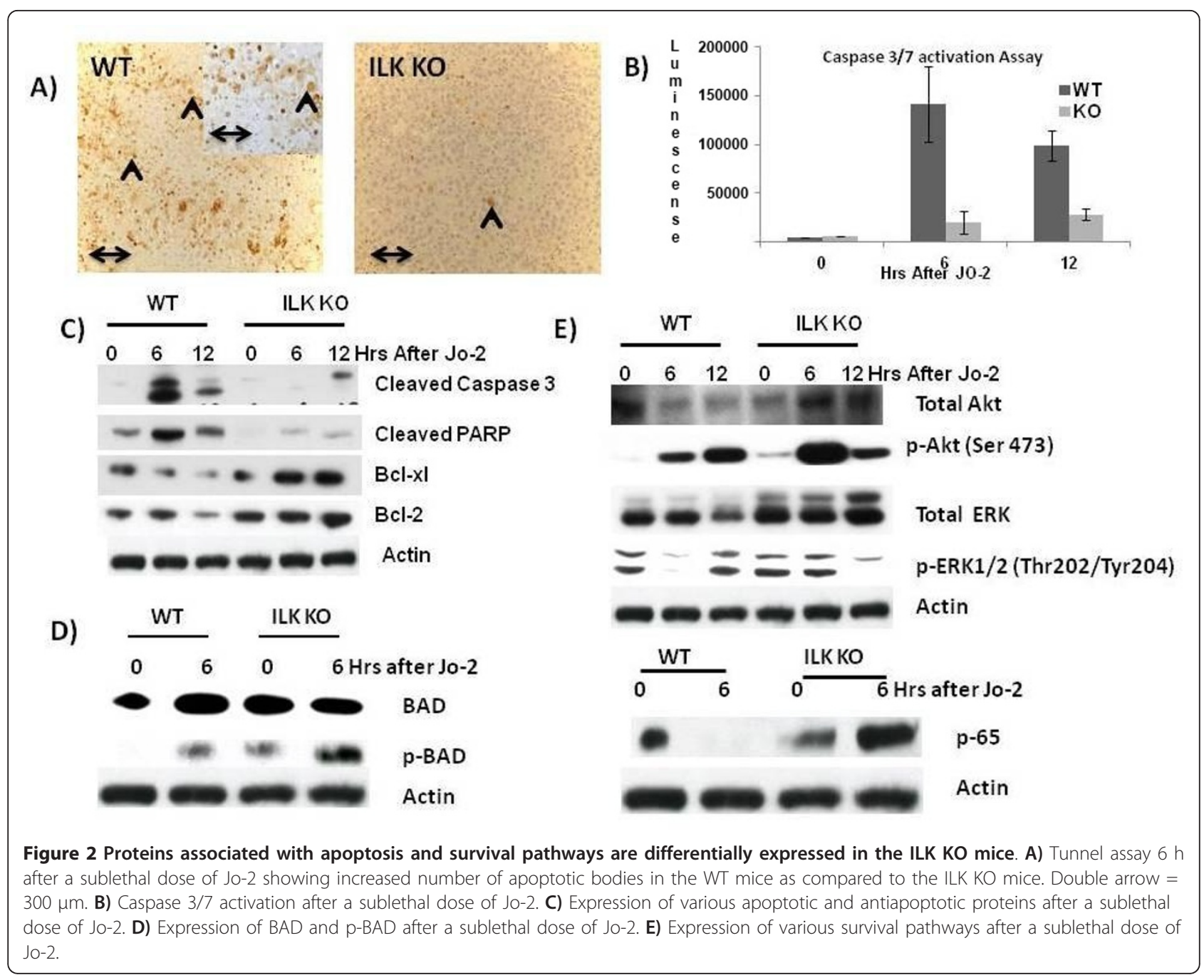

in the ILK KO mice after JO-2 administration as compared to the control mice. The basal level of p-BAD was also higher in the ILK KO mice as compared to the controls (Figure 2D). Expression of p-BAD in control was barely detectable at basal levels (Figure 2D).

To understand the molecular events underlying the resistance of ILK KO mice to Jo-2 induced apoptosis, we examined the activation of several survival pathways known to be involved in cytoprotection against Fasinduced apoptosis. We investigated phosphorylation of Akt, Erk1/2, and NF $\kappa \mathrm{B}$ activation which are known to be involved in cytoprotection against Fas-induced apoptosis $[1,12,16,17]$. There was an induction of both total and p-Akt after Jo-2 administration both in ILK KO and control mice at 6 and $12 \mathrm{~h}$ after Jo-2 administration (Figure 2E). The induction was more enhanced in the ILK KO mice than the controls at $6 \mathrm{~h}$ after Jo-2 administration (Figure 2E). Basal level of p-Akt was also higher in the ILK KO mice as compared to the controls. Levels of p-Erk $1 / 2$ levels at $6 \mathrm{~h}$ decreased after Jo- 2 administration in the controls while they remain stable in the ILK $\mathrm{KO}$ mice (Figure 2E). Levels of total ERK were also slightly lower in the WT than ILK KO. Also, levels of the NFkB subunit p65 go down after Jo-2 in the control mice at $6 \mathrm{~h}$ while they were upregulated in the ILK KO mice. The basal level of p65 was also higher in the ILK $\mathrm{KO}$ mice as compared to the controls (Figure 2E). These studies suggest that the survival signaling machinery is upregulated in the ILK KO as compared to the controls before and after Jo-2 administration.

Phosphorylation of ERK1/2 and NF $\kappa \mathrm{B}$ activation are primarily responsible for protecting ILK KO hepatocytes from apoptosis

Consistent with our in vivo data, hepatocytes isolated from ILK KO mice were resistant to Jo-2 and Actinomycin D induced apoptosis (Figure 3A). Our in vivo data suggest that increase in survival pathways like Akt, 


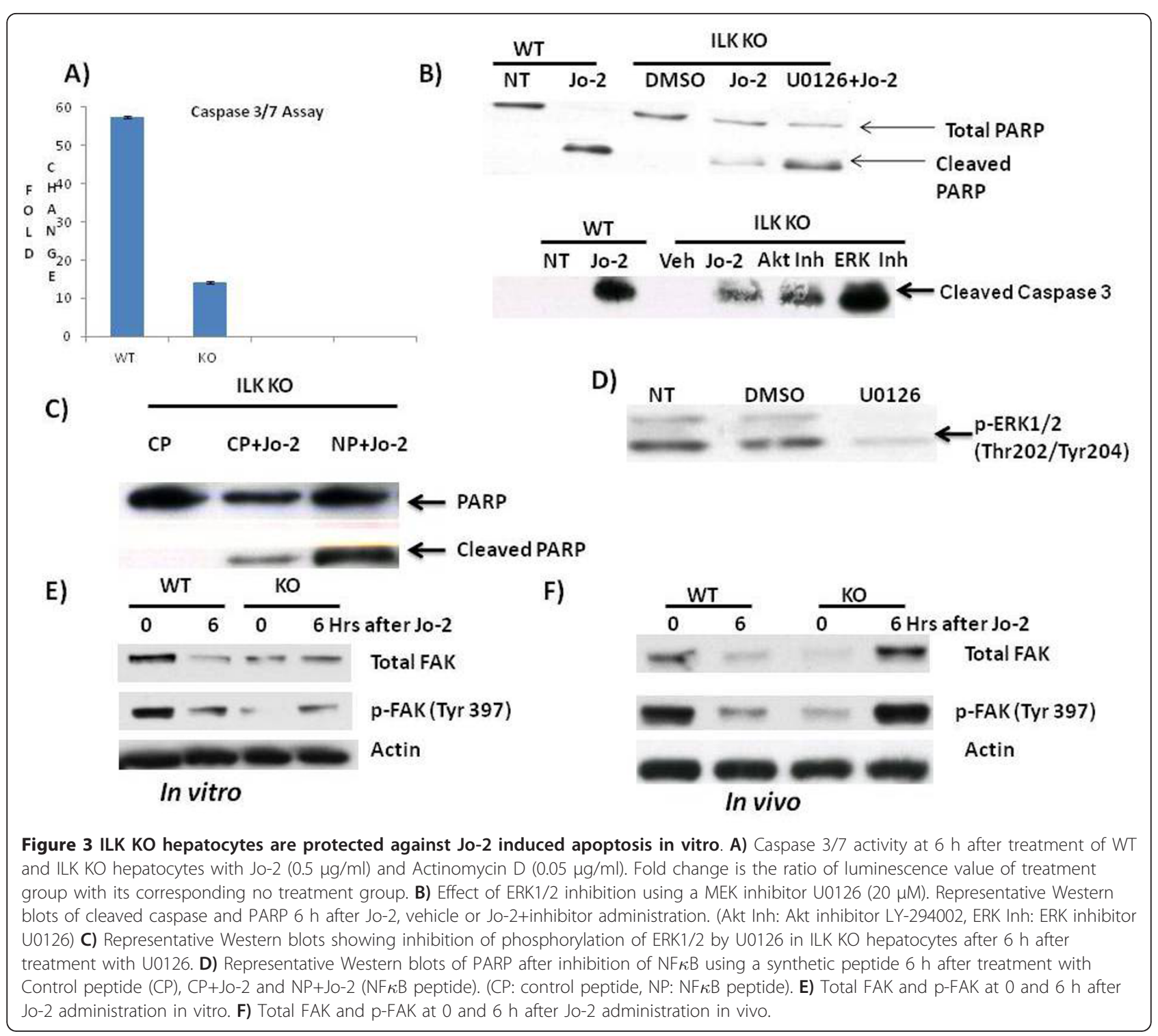

Erk $1 / 2$ and $\mathrm{NF} \kappa \mathrm{B}$ plays a role in affording this protection. We used pharmacological inhibitors for Akt and Erk $1 / 2$ and peptide inhibitor for $\mathrm{NF} \kappa \mathrm{B}$. Inhibition of Erk1/2 and NF $\kappa \mathrm{B}$ led to increased susceptibility of ILK $\mathrm{KO}$ hepatocytes to Jo-2 and Actinomycin D induced apoptosis (Figure 3B and 3C). Pharmacological inhibitor against ERK1/2 was effective in downregulating the phosphorylation of ERK (Figure 3D). Inhibition of Akt did not have any effect (Figure 3B). Thus, NF $\kappa \mathrm{B}$ and Erk1/2 but not Akt seem to be involved in affording protection to ILK KO hepatocytes to Jo-2 and actinomycin D induced apoptosis.

Focal adhesion kinase signaling

Focal adhesion kinase is another enzyme associated with integrin signaling $[18,19]$. We looked into the possibility of FAK signaling compensating for the loss of ILK signaling. Genetic removal of ILK led to lower expression of FAK in the whole liver as well as hepatocytes isolated from the ILK KO mice ( $0 \mathrm{~h}$ of Figure 3E and 3F). Activation of FAK as a result of tyrosine phosphorylation at 397 residue was also lower in the whole liver as well as hepatocytes of the ILK KO mice $(0 \mathrm{~h}$ of Figure 3E and $3 \mathrm{~F})$. Interestingly, administration of Jo-2 both in vivo and in vitro resulted in an increase in total as well as activated FAK in the ILK KO mice (Figure 3E and 3F). The WT mice on the other hand showed downregulation of total and activated FAK after Jo-2 administration both in vivo and in vitro. Several studies have shown the protective role of FAK in apoptosis [20-22]. Thus, upregulation of FAK signaling in the ILK KO mice after Jo-2 administration may also be playing an important 
role in protection against Jo-2 induced apoptosis. Interventional studies will provide a better understanding of the role of FAK signaling in Jo-2 induced apoptosis in absence of ILK signaling.

\section{Discussion}

In this study we show that ILK is plays a regulatory role in Fas mediated apoptosis. We present evidence that hepatocyte specific ILK KO mice are resistant to Fas-induced apoptosis both in vivo and in vitro. Furthermore we show that apoptotic injury in the ILK KO mice is associated with an increase in antiapoptotic genes like Bcl-xl and Bcl2. Investigation of the mechanism behind this protection revealed reduced expression of the Fas receptor in the ILK KO mice. However, the lower expression of Fas receptor in the ILK KO mice is not the only mechanism that could afford that much protection. Thus, we looked at the other possibilities that might also contribute to this protection. The survival program of ILK is well established and includes primarily activation of PI3K/Akt, ERK1/2 and $\mathrm{NF} \kappa \mathrm{B}$ pathway $[6,7,23-25]$. In agreement to these studies we found induction of PI3K/Akt, ERK1/2 and NF $\kappa$ B not only after Jo-2 administration but also at basal levels in the ILK KO mice. We then used a well described in the literature in vitro system of studying hepatocyte apoptosis using Jo-2 and Actinomycin D. Pharmacological inhibition of ERK using U0126 and peptide inhibition of NF $\kappa \mathrm{B}$ pathway led to increased susceptibility of ILK KO hepatocytes to Jo-2 induced apoptosis in hepatocyte cultures, suggesting that ERK and NF $\kappa$ B pathways but were the signaling mediators for ILK in this process. Inhibition of Akt using PI3K inhibitor LY-294002 did not affect the degree of apoptosis in ILK KO hepatocytes. Together the data suggests that reduced expression of FAS receptor in the ILK KO mice along with persistent upregulation of survival signals like ERK1/2 and NF $\kappa \mathrm{B}$ signaling is the mechanism behind protection of ILK KO mice against Jo-2 induced liver failure.

It should be noted that our results differ to previously published literature where upregulation of ILK in mammary epithelial cells protects against apoptosis [26]. It is conceivable that ILK may be promoting apoptosis in the liver while it has a completely opposite role in the mammary glands. Also, genetic elimination of a protein results in many adaptive changes in the organ. It is likely that genetic removal of ILK from the liver results in adaptive changes in the liver that make them resistant to apoptosis. Liver and mammary gland tissues also have different life cycles. Differentiation of liver tends to be stable through life whereas mammary glands undergo dramatic changes in their differentiation both due to hormonal cycles as well as during pregnancy.

A relevant question is why genetic ablation of ILK led to increased activation of these survival pathways? Our current studies as well as those we recently published
[10,27-29] suggest that ILK mediated signaling plays a regulatory role the balance between proliferation and apoptosis in hepatocytes. Previous studies from our laboratory have also shown that in situations in which mitogenic signals to hepatocytes via EGFR or MET are suppressed, there is up-regulation of pro-apoptotic pathways and down-regulation of anti-apoptotic pathways [30,31]. The delicate balance between hepatocyte proliferation versus apoptosis underlies pathways leading to liver regeneration or liver failure. ILK has been shown to have many roles in tumor development, with studies describing different effects in different tumors based on tissue origin $[24,25,32,33]$. The signaling pathways by which ILK affects these phenomena were not clear. Our current studies with hepatocyte cultures show that at least in hepatocytes, the effects of ILK on hepatocyte survival are mediated via NFkB and ERK signaling. These signaling pathways also have well known effects on hepatocyte proliferation, and ILK seems to play a suppressive role in that regard (ILK KO hepatocytes have enhanced proliferation, [10,27].

\section{Conclusions}

Here we report that genetic ablation of ILK from hepatocytes protects from Jo-2 induced apoptosis due to upregulation of survival signaling mainly ERK, FAK and $\mathrm{NF} \kappa \mathrm{B}$ signaling. The findings of this work provide a mechanistic interpretation of the ILK role in these processes and underscore the complex role of ILK and integrin signaling in control of proliferation, survival or death of hepatocytes.

\section{Acknowledgements}

The work was supported by grants R01CA035373-26 and R01 CA103958.

\section{Authors' contributions}

SD conducted the animal studies, collected tissues, performed Western blotting and wrote the manuscript. WM did the genotyping and gave technical assistance. AO performed the immunohistochemical staining. CW gave technical assistance. GM designed the study, examined histological and immunohistochemical staining, and reviewed the manuscript. All the authors have read and approved the final manuscript.

\section{Competing interests}

The authors declare that they have no competing interests.

Received: 22 July 2011 Accepted: 21 November 2011

Published: 21 November 2011

\section{References}

1. Canbay A, Friedman S, Gores GJ: Apoptosis: the nexus of liver injury and fibrosis. Hepatology 2004, 39(2):273-278.

2. Ibrahim SH, Kohli R, Gores GJ: Mechanisms of Lipotoxicity in NAFLD and Clinical Implications. J Pediatr Gastroenterol Nutr 2011, 53(2):131-140.

3. St-Pierre MV, Dufour JF: Biomarkers for Hepatocellular Apoptosis in the Management of Liver Diseases. Curr Pharm Biotechnol.

4. Guicciardi ME, Gores GJ: Apoptosis as a mechanism for liver disease progression. Semin Liver Dis 2010, 30(4):402-410.

5. Ogasawara J, Watanabe-Fukunaga R, Adachi M, Matsuzawa A, Kasugai T, Kitamura Y, Itoh N, Suda T, Nagata S: Lethal effect of the anti-Fas antibody in mice. Nature 1993, 364(6440):806-809. 
6. Legate KR, Montanez E, Kudlacek O, Fassler R: ILK, PINCH and parvin: the tIPP of integrin signalling. Nat Rev Mol Cell Biol 2006, 7(1):20-31.

7. Wu C: The PINCH-ILK-parvin complexes: assembly, functions and regulation. Biochim Biophys Acta 2004, 1692(2-3):55-62.

8. Zhang Y, Chen K, Tu Y, Velyvis A, Yang Y, Qin J, Wu C: Assembly of the PINCH-ILK-CH-ILKBP complex precedes and is essential for localization of each component to cell-matrix adhesion sites. J Cell Sci 2002, 115(Pt 24):4777-4786

9. Gkretsi V, Mars WM, Bowen WC, Barua L, Yang Y, Guo L, St-Arnaud R, Dedhar S, Wu C, Michalopoulos GK: Loss of integrin linked kinase from mouse hepatocytes in vitro and in vivo results in apoptosis and hepatitis. Hepatology 2007, 45(4):1025-1034.

10. Gkretsi V, Apte U, Mars WM, Bowen WC, Luo JH, Yang Y, Yu YP, Orr A, StArnaud R, Dedhar S, Kaestner KH, Wu C, Michalopoulos GK: Liver-specific ablation of integrin-linked kinase in mice results in abnormal histology, enhanced cell proliferation, and hepatomegaly. Hepatology 2008, 48(6):1932-1941.

11. Terpstra L, Prud'homme J, Arabian A, Takeda S, Karsenty G, Dedhar S, StArnaud R: Reduced chondrocyte proliferation and chondrodysplasia in mice lacking the integrin-linked kinase in chondrocytes. J Cell Biol 2003, 162(1):139-148.

12. Berasain C, Garcia-Trevijano ER, Castillo J, Erroba E, Santamaria M, Lee DC, Prieto J, Avila MA: Novel role for amphiregulin in protection from liver injury. J Biol Chem 2005, 280(19):19012-19020.

13. Gomez-Quiroz LE, Factor VM, Kaposi-Novak P, Coulouarn C, Conner EA, Thorgeirsson SS: Hepatocyte-specific c-Met deletion disrupts redox homeostasis and sensitizes to Fas-mediated apoptosis. J Biol Chem 2008, 283(21):14581-14589.

14. Reed JC, Zha H, Aime-Sempe C, Takayama S, Wang HG: Structure-function analysis of $\mathrm{Bcl}-2$ family proteins. Regulators of programmed cell death. Adv Exp Med Biol 1996, 406:99-112.

15. Zhai D, Ke N, Zhang H, Ladror U, Joseph M, Eichinger A, Godzik A, Ng SC, Reed JC: Characterization of the anti-apoptotic mechanism of $\mathrm{BCl}-\mathrm{B}$. Biochem J 2003, 376(Pt 1):229-236.

16. Huh CG, Factor VM, Sanchez A, Uchida K, Conner EA, Thorgeirsson SS: Hepatocyte growth factor/c-met signaling pathway is required for efficient liver regeneration and repair. Proc Natl Acad Sci USA 2004, 101(13):4477-4482.

17. Marques JM, Belza I, Holtmann B, Pennica D, Prieto J, Bustos M: Cardiotrophin-1 is an essential factor in the natural defense of the liver against apoptosis. Hepatology 2007, 45(3):639-648.

18. Boudreau NJ, Jones PL: Extracellular matrix and integrin signalling: the shape of things to come. Biochem J 1999, 339(Pt 3):481-488.

19. Mitra SK, Hanson DA, Schlaepfer DD: Focal adhesion kinase: in command and control of cell motility. Nat Rev Mol Cell Biol 2005, 6(1):56-68.

20. Hao H, Naomoto Y, Bao X, Watanabe N, Sakurama K, Noma K, Motoki T, Tomono Y, Fukazawa T, Shirakawa Y, Yamatsuji T, Matsuoka J, Wang ZG, Takaoka M: Focal adhesion kinase as potential target for cancer therapy (Review). Oncol Rep 2009, 22(5):973-979.

21. Sonoda Y, Matsumoto Y, Funakoshi M, Yamamoto D, Hanks SK, Kasahara T: Anti-apoptotic role of focal adhesion kinase (FAK). Induction of inhibitorof-apoptosis proteins and apoptosis suppression by the overexpression of FAK in a human leukemic cell line, HL-60. J Biol Chem 2000, 275(21):16309-16315

22. Sonoda Y, Watanabe S, Matsumoto Y, Aizu-Yokota E, Kasahara T: FAK is the upstream signal protein of the phosphatidylinositol 3-kinase-Akt survival pathway in hydrogen peroxide-induced apoptosis of a human glioblastoma cell line. J Biol Chem 1999, 274(15):10566-10570.

23. Dedhar S, Williams B, Hannigan G: Integrin-linked kinase (ILK): a regulator of integrin and growth-factor signalling. Trends Cell Biol 1999, 9(8):319-323.

24. Hannigan G, Troussard AA, Dedhar S: Integrin-linked kinase: a cancer therapeutic target unique among its ILK. Nat Rev Cancer 2005, 5(1):51-63.

25. Hehlgans S, Haase $M$, Cordes N: Signalling via integrins: implications for cell survival and anticancer strategies. Biochim Biophys Acta 2007, 1775(1):163-180

26. Persad S, Attwell S, Gray V, Delcommenne M, Troussard A, Sanghera J, Dedhar S: Inhibition of integrin-linked kinase (ILK) suppresses activation of protein kinase B/Akt and induces cell cycle arrest and apoptosis of PTEN-mutant prostate cancer cells. Proc Natl Acad Sci USA 2000, 97(7):3207-3212
27. Apte U, Gkretsi V, Bowen WC, Mars WM, Luo JH, Donthamsetty S, Orr A, Monga SP, Wu C, Michalopoulos GK: Enhanced liver regeneration following changes induced by hepatocyte-specific genetic ablation of integrin-linked kinase. Hepatology 2009, 50(3):844-851.

28. Donthamsetty S, Bhave VS, Kliment CS, Bowen WC, Mars WM, Bell AW, Stewart RE, Orr A, Wu C, Michalopoulos GK: Excessive hepatomegaly of mice with hepatocyte-targeted elimination of integrin linked kinase following treatment with 1,4-bis [2-(3,5-dichaloropyridyloxy)] benzene. Hepatology 2011, 53(2):587-595.

29. Donthamsetty S, Bowen W, Mars W, Bhave V, Luo JH, Wu C, Hurd J, Orr A, Bell A, Michalopoulos G: Liver-specific ablation of integrin-linked kinase in mice results in enhanced and prolonged cell proliferation and hepatomegaly after phenobarbital administration. Toxicol Sci 2010, 113(2):358-366.

30. Paranjpe S, Bowen WC, Bell AW, Nejak-Bowen K, Luo JH, Michalopoulos GK: Cell cycle effects resulting from inhibition of hepatocyte growth factor and its receptor c-Met in regenerating rat livers by RNA interference. Hepatology 2007, 45(6):1471-1477.

31. Paranjpe S, Bowen WC, Tseng GC, Luo JH, Orr A, Michalopoulos GK: RNA interference against hepatic epidermal growth factor receptor has suppressive effects on liver regeneration in rats. Am J Pathol 2010, 176(6):2669-2681.

32. Hannigan GE, McDonald PC, Walsh MP, Dedhar S: Integrin-linked kinase: Not so 'pseudo' after all. Oncogene 2011, 30(43):4375-85.

33. Persad S, Dedhar S: The role of integrin-linked kinase (ILK) in cancer progression. Cancer Metastasis Rev 2003, 22(4):375-384.

doi:10.1186/1476-5926-10-11

Cite this article as: Donthamsetty et al:: Protection against Fas-induced fulminant hepatic failure in liver specific integrin linked kinase knockout mice. Comparative Hepatology 2011 10:11.

\section{Submit your next manuscript to BioMed Central and take full advantage of:}

- Convenient online submission

- Thorough peer review

- No space constraints or color figure charges

- Immediate publication on acceptance

- Inclusion in PubMed, CAS, Scopus and Google Scholar

- Research which is freely available for redistribution

Submit your manuscript at www.biomedcentral.com/submit
C) Biomed Central 